\title{
Two Year Follow-Up of a Primary Care-Based Intervention to Prevent and Manage Childhood Obesity: The High Five for Kids Study
}

Sheryl L. Rifas-Shiman, $\mathrm{MPH}^{1}$, Elsie M. Taveras, MD, $\mathrm{MPH}^{2}$, Steven L. Gortmaker, $\mathrm{PhD}^{3}$, Katherine H. Hohman, $\mathrm{MPH}^{4}$, Christine M. Horan, $\mathrm{MPH}^{2}$, Ken P. Kleinman, $\mathrm{ScD}^{1}$, Kathleen Mitchell, MD ${ }^{5}$, Sarah Price, $\mathrm{MPH}^{2}$, Lisa A. Prosser, $\mathrm{PhD}^{6}$, Matthew W. Gillman, MD, SM ${ }^{1}$

${ }^{1}$ Obesity Prevention Program, Department of Population Medicine, Harvard Medical School and Harvard Pilgrim Health Care Institute, Boston, MA; ${ }^{2}$ Division of General Academic Pediatrics, Department of Pediatrics, Massachusetts General Hospital for Children, Boston, MA;

${ }^{3}$ Department of Social and Behavioral Sciences, Harvard T.H. Chan School of Public Health Boston, MA; ${ }^{4}$ Healthy Living Department, YMCA of the USA, Chicago, IL; ${ }^{5}$ Harvard Vanguard Medical Associates, Watertown, MA; ${ }^{6}$ Child Health Evaluation and Research Unit, Division of General Pediatrics, University of Michigan Health System, Ann Arbor, Michigan.

Corresponding author: Sheryl L. Rifas-Shiman, MPH, Department of Population Medicine, Harvard Medical School and Harvard Pilgrim Health Care Institute, 401 Park Drive, Suite 401, Boston, MA 02215. Telephone: 617-867-4824. E-mail: sheryl_rifas@hphc.org

Conflict of interest statement: The authors report no conflicts of interest.

Funding statement: This study was supported by a grant from the Eunice Kennedy Shriver National Institute of Child Health and Human Development (R01 HD 050966).

clinicaltrials.gov Identifier: NCT00377767

This is the author manuscript accepted for publication and has undergone full peer review but has not been through the copyediting, typesetting, pagination and proofreading process, which may lead to differences between this version and the Version of Record. Please cite this article as doi: 10.1111/ijpo.12141

This article is protected by copyright. All rights reserved. 
Word Count: Abstract 169; Text 967

Running head: Two-year follow-up of an obesity intervention

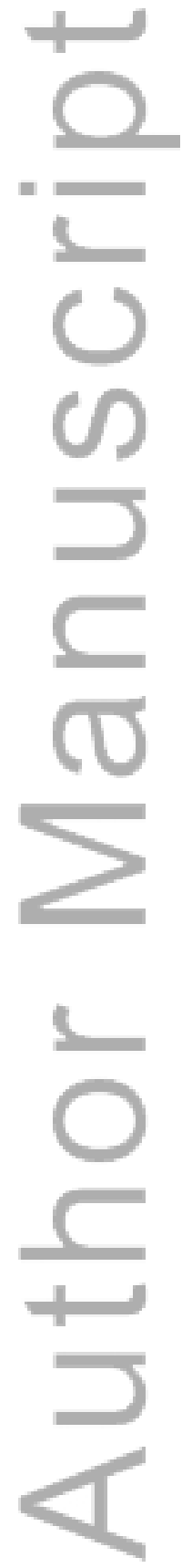

This article is protected by copyright. All rights reserved. 


\begin{abstract}
We examined 2-year changes in age- and sex-specific BMI z-scores and obesity-related behaviors among 441 of the 475 originally recruited participants in High Five for Kids, a cluster randomized controlled trial in 10 pediatric practices. The intervention included a more intensive 1-year intervention period ( 4 in-person visits and 2 phone calls) followed by a less intensive 1year maintenance period ( 2 in-person visits) among children who were overweight or obese and age 2-6 years at enrollment. The five intervention practices restructured care to manage these children including motivational interviewing and educational modules targeting television viewing and intakes of fast food and sugar sweetened beverages. After 2 years, compared with usual care, intervention participants had similar changes in BMI z-scores (-0.04 units; 95\% CI $-0.14,0.06)$, television viewing $(-0.20$ hours/day; -0.49 to 0.09$)$, and intakes of fast food $(-0.09$ servings/week; -0.34 to 0.17$)$ and sugar sweetened beverages $(-0.26$ servings/day; -0.67 to
\end{abstract} 0.14). High Five for Kids, a primarily clinical-based intervention, did not affect BMI z-scores or obesity-related behaviors after 2 years.

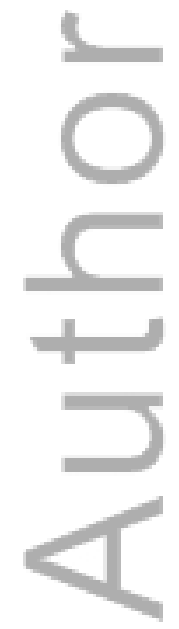




\section{Background}

In the United States in 2011-2012, approximately 14.4\% of children age 2-5 years were overweight (age- and sex-specific BMI in the $85^{\text {th }}$ to $<95^{\text {th }}$ percentile) and $8.4 \%$ were obese (BMI $\geq 95^{\text {th }}$ percentile). ${ }^{1}$ Most childhood obesity is incident by the age of 5 years, ${ }^{2}$ making prevention in the preschool years a priority.

Obesity prevention interventions in primary care settings targeting preschool-age children may be beneficial because children of this age visit their primary care clinicians frequently for routine medical care; parents have more control over their children's health-related behaviors; and these behaviors may be more malleable.

High Five for Kids was a primary care-based obesity intervention among children age 2-6 years. The intervention consisted of a more intensive 1-year intervention period followed by a less intensive 1-year maintenance period. After 1 year, we reported that the intervention did not reduce BMI z-scores (-0.05 units; $95 \%$ CI -0.14, 0.04) or intakes of fast food and sugar sweetened beverages, but was effective in reducing television viewing $(-0.36$ hours/day; $95 \%$ CI, -0.64 to -0.09$).{ }^{3}$ The purpose of this study was to assess the effectiveness of the intervention after the planned 2-year intervention period.

\section{Methods}

High Five for Kids was a cluster randomized controlled trial to reduce obesity in 10 pediatric practices (5 intervention, 5 usual care) of Harvard Vanguard Medical Associates, a multisite group practice in Massachusetts. ${ }^{3}$ We enrolled 271 intervention and 204 usual care 
children age 2-6 years with $\mathrm{BMI} \geq 95^{\text {th }}$ percentile, or $85^{\text {th }}$ to $<95^{\text {th }}$ percentile if at least 1 parent was overweight $\left(\mathrm{BMI} \geq 25 \mathrm{~kg} / \mathrm{m}^{2}\right) ; 253$ intervention and 192 usual care children had 1-year outcomes; 249 intervention (93\% of those enrolled) and 192 usual care (93\% of those enrolled) children had 2-year outcomes. The overarching model for this intervention was the Chronic Care Model, which posits that changes in primary care to produce functional patient outcomes require changes for all members of the practice team. Intervention practices received primary care restructuring, and families received motivational interviewing by clinicians and educational modules targeting television viewing and intakes of fast food and sugar sweetened beverages. During the 1-year intervention period, we aimed for participants to complete 4 in-person visits and 2 phone calls with clinicians. During the subsequent 1-year maintenance period, we aimed for participants to complete 2 in-person intervention visits. Details of the recruitment, randomization, and the intervention through 1 year have been described elsewhere. ${ }^{3}$ The institutional review board of Harvard Pilgrim Health Care approved all study procedures. Our primary outcome was change in BMI z-scores from baseline to 2 years. During routine clinical visits, medical assistants measured children's weight and height, and we calculated age- and sex-specific BMI z-scores using US national reference data. ${ }^{5}$ Secondary outcomes were changes in duration of television viewing and intakes of fast food and sugar sweetened beverages from baseline to 2 years. We used validated questions to assess duration of television viewing and intakes of fast food and sugar sweetened beverages. ${ }^{6-8}$ We first examined baseline distributions of child and parent characteristics by intervention status. In intent-to-treat analyses, we used unadjusted and multivariable adjusted linear regression models to estimate 
differences from baseline to 2 years between the intervention and usual care groups. We adjusted for child age, sex, and race/ethnicity; parent education and overweight/obesity status at baseline; household income; and time elapsed from baseline to follow-up visit. In all models, we performed generalized linear mixed models that accounted for clustering by practices.

\section{Results}

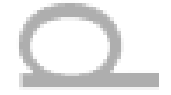

At baseline, the mean (SD) age was 4.9 (1.2) years. Mean (SD) BMI was 19.2 (2.6) among intervention children and 19.1 (2.0) among usual care children and BMI z-scores were $1.88(0.69)$ and $1.82(0.56)$, respectively. Children in intervention clinics had a higher percent of racial/ethnic minorities (53\% v. 30\%), an obese parent (61\% v. 44\%), and lived in lower-income households (35\% v. $20 \% \leq \$ 50,000 /$ year). There were no group differences at baseline in health behaviors. (Table 1) Among the 253 intervention participants, $62 \%$ of participants completed 0 visits, $17 \%$ completed 1 visit, and $21 \%$ completed 2 of the 2 intervention visits during the 1 -year maintenance period.

At 2 years follow-up, the mean (SD) age of participants was 7.0 (1.2) years. BMI had increased by a mean of $1.1 \mathrm{~kg} / \mathrm{m}^{2}$ in the intervention group and $1.2 \mathrm{~kg} / \mathrm{m}^{2}$ in the usual care group corresponding to decreases in BMI z-scores in both groups (-0.20 and -0.18 , respectively). In adjusted models, compared with usual care, participants in intervention clinics had similar changes in BMI z-scores (-0.04 units; 95\% CI -0.14, 0.06), television viewing ( -0.20 hours/day; $95 \% \mathrm{CI}-0.49$ to 0.09$)$, and intakes of fast food ( -0.09 servings/week; $95 \% \mathrm{CI}-0.34$ to 0.17$)$ and sugar sweetened beverages $(-0.26$ serving/day; $95 \% \mathrm{CI}-0.67$ to 0.14$)$ relative to participants in 
usual care clinics. (Table 2) We did not observe any differences in outcomes according to subgroups defined by child age, sex or race/ethnicity, by parent education or overweight/obesity status, or by household income.

\section{Discussion}

In summary, after 2 years, the High Five for Kids intervention did not appreciably $=$ improve BMI z-scores or obesity-related behaviors compared with children not receiving the intervention. At least two factors could have contributed to the lack of intervention effect on BMI z-scores. First, our intervention involved only the primary care setting and not children's communities or environment. It is possible that primary care-based interventions alone will not effect change in BMI z-scores but could complement and potentially enhance more comprehensive efforts in multiple settings. Second, adherence to intervention activities was low during the 1-year maintenance period. It is possible that the intervention "dose" delivered during the 1-year maintenance period was not sufficient in effecting changes in BMI z-scores. However, even at 1 year, High Five for Kids did not show an effect on BMI z-scores. ${ }^{3}$ Obesity prevention interventions in children may require more contact hours and/or additional settings to be effective.

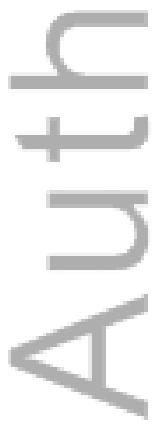




\section{References}

1. Ogden CL, Carroll MD, Kit BK, Flegal KM. Prevalence of Childhood and Adult Obesity in the United States, 2011-2012. JAMA. 2014;311(8):806-814

2. Gillman MW, Ludwig DS. How Early Should Obesity Prevention Start? N Engl J Med 2013; 369:2173-2175.

3. Taveras EM, Gortmaker SL, Hohman KH, et al. Randomized controlled trial to improve primary care to prevent and manage childhood obesity: the High Five for Kids study.

Arch Pediatr Adolesc Med. 2011 Aug;165(8):714-22.

4. Wagner EH. Chronic disease management: what will it take to improve care for chronic illness? Eff Clin Pract. 1998;1(1):2-4.

5. National Center for Health Statistics. CDC Growth Charts, United States. <http://www.cdc.gov/growthcharts/> (2000).

6. Baker PC, Keck CK, Mott FL, Quinlan SV. NLSY Child Handbook: A Guide to the 1986-90 National Longitudinal Survey of Youth Child Data. Rev ed. Columbus: Center for Human Resource Research, Ohio State University; 1993.

7. Blum RE, Wei EK, Rockett HR, et al. Validation of a food frequency questionnaire in Native American and Caucasian children 1 to 5 years of age. Matern Child Health J. $1999 ; 3(3): 167-172$.

8. Taveras EM, Berkey CS, Rifas-Shiman SL, et al. Association of consumption of fried food away from home with body mass index and diet quality in older children and adolescents. Pediatrics. 2005;116(4):e518-e524.

This article is protected by copyright. All rights reserved. 
9. Wen X, Gillman MW, Rifas-Shiman SL, Sherry B, Kleinman K, Taveras EM.

Decreasing prevalence of obesity among young children in Massachusetts from 2004 to 2008. Pediatrics. 2012 May;129(5):823-31.

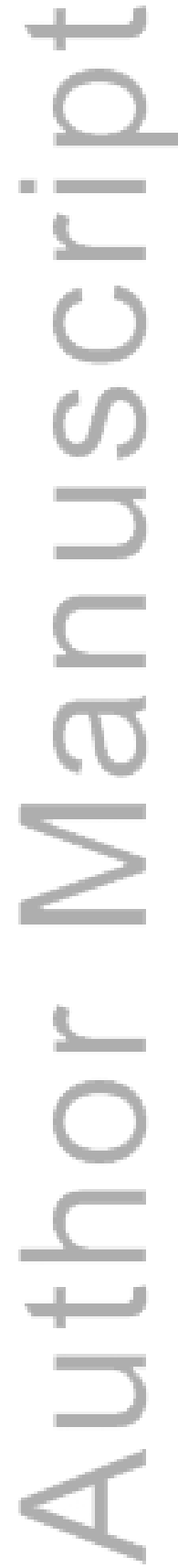

This article is protected by copyright. All rights reserved. 


\section{Please wait...}

If this message is not eventually replaced by the proper contents of the document, your PDF viewer may not be able to display this type of document.

You can upgrade to the latest version of Adobe Reader for Windows®, Mac, or Linux® by visiting http://www.adobe.com/go/reader_download.

For more assistance with Adobe Reader visit http://www.adobe.com/go/acrreader.

Windows is either a registered trademark or a trademark of Microsoft Corporation in the United States and/or other countries. Mac is a trademark of Apple Inc., registered in the United States and other countries. Linux is the registered trademark of Linus Torvalds in the U.S. and other countries.
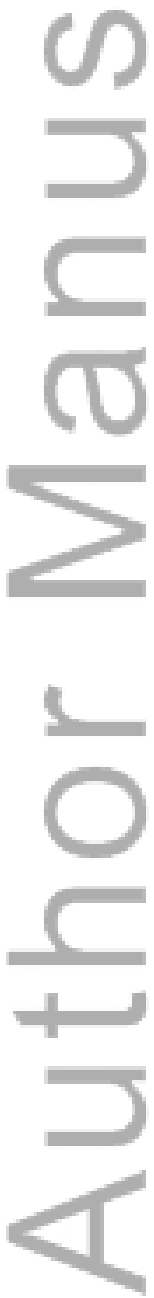


\section{Please wait...}

If this message is not eventually replaced by the proper contents of the document, your PDF viewer may not be able to display this type of document.

You can upgrade to the latest version of Adobe Reader for Windows®, Mac, or Linux® by visiting http://www.adobe.com/go/reader_download.

For more assistance with Adobe Reader visit http://www.adobe.com/go/acrreader.

Windows is either a registered trademark or a trademark of Microsoft Corporation in the United States and/or other countries. Mac is a trademark of Apple Inc., registered in the United States and other countries. Linux is the registered trademark of Linus Torvalds in the U.S. and other countries.
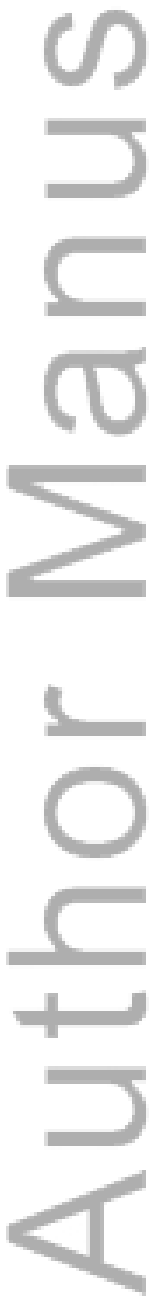


\section{Please wait...}

If this message is not eventually replaced by the proper contents of the document, your PDF viewer may not be able to display this type of document.

You can upgrade to the latest version of Adobe Reader for Windows®, Mac, or Linux® by visiting http://www.adobe.com/go/reader_download.

For more assistance with Adobe Reader visit http://www.adobe.com/go/acrreader.

Windows is either a registered trademark or a trademark of Microsoft Corporation in the United States and/or other countries. Mac is a trademark of Apple Inc., registered in the United States and other countries. Linux is the registered trademark of Linus Torvalds in the U.S. and other countries.
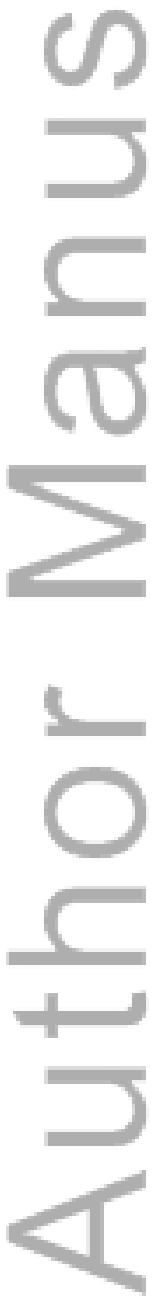
To view the full contents of this document, you need a later version of the PDF viewer. You can upgrade to the latest version of Adobe Reader from www.adobe.com/products/acrobat/readstep2.html

For further support, go to www.adobe.com/support/products/acrreader.html

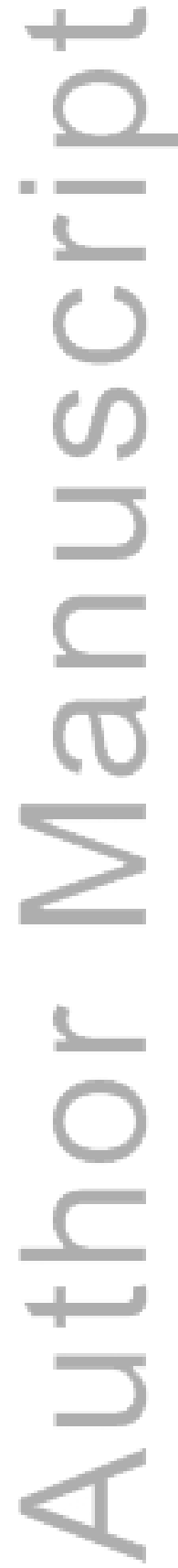

This article is protected by copyright. All rights reserved. 


\section{Please wait...}

If this message is not eventually replaced by the proper contents of the document, your PDF viewer may not be able to display this type of document.

You can upgrade to the latest version of Adobe Reader for Windows®, Mac, or Linux® by visiting http://www.adobe.com/go/reader_download.

For more assistance with Adobe Reader visit http://www.adobe.com/go/acrreader.

Windows is either a registered trademark or a trademark of Microsoft Corporation in the United States and/or other countries. Mac is a trademark of Apple Inc., registered in the United States and other countries. Linux is the registered trademark of Linus Torvalds in the U.S. and other countries.
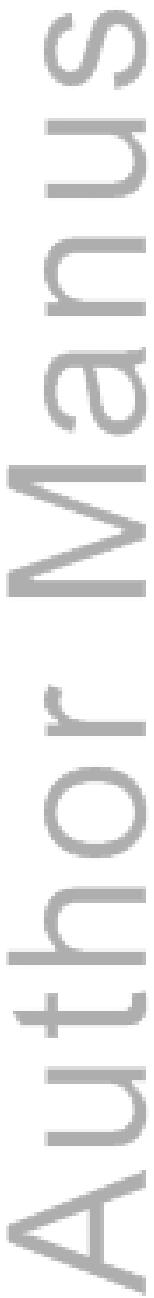


\section{Please wait...}

If this message is not eventually replaced by the proper contents of the document, your PDF viewer may not be able to display this type of document.

You can upgrade to the latest version of Adobe Reader for Windows®, Mac, or Linux® by visiting http://www.adobe.com/products/acrobat/readstep2.html.

For more assistance with Adobe Reader visit http://www.adobe.com/support/products/ acrreader.html.

Windows is either a registered trademark or a trademark of Microsoft Corporation in the United States and/or other countries. Mac is a trademark of Apple Inc., registered in the United States and other countries. Linux is the registered trademark of Linus Torvalds in the U.S. and other countries.

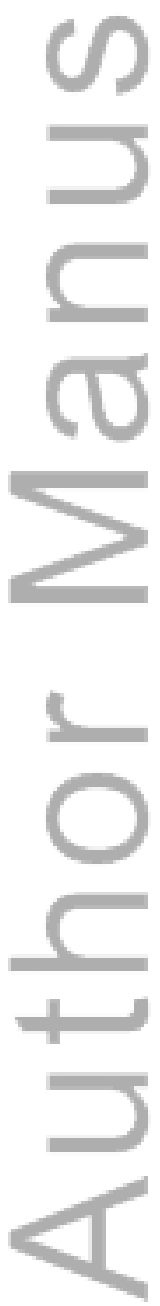




\section{Please wait...}

If this message is not eventually replaced by the proper contents of the document, your PDF viewer may not be able to display this type of document.

You can upgrade to the latest version of Adobe Reader for Windows®, Mac, or Linux® by visiting http://www.adobe.com/products/acrobat/readstep2.html.

For more assistance with Adobe Reader visit http://www.adobe.com/support/products/ acrreader.html.

Windows is either a registered trademark or a trademark of Microsoft Corporation in the United States and/or other countries. Mac is a trademark of Apple Inc., registered in the United States and other countries. Linux is the registered trademark of Linus Torvalds in the U.S. and other countries.

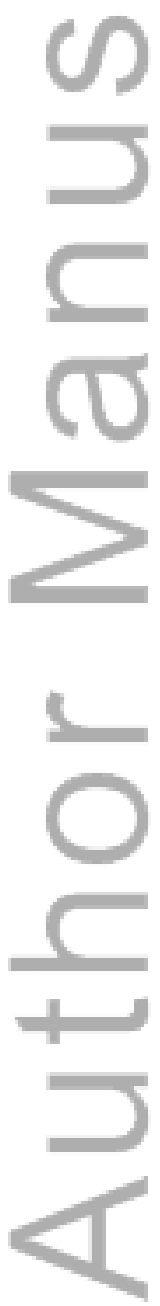




\section{Please wait...}

If this message is not eventually replaced by the proper contents of the document, your PDF viewer may not be able to display this type of document.

You can upgrade to the latest version of Adobe Reader for Windows®, Mac, or Linux® by visiting http://www.adobe.com/products/acrobat/readstep2.html.

For more assistance with Adobe Reader visit http://www.adobe.com/support/products/ acrreader.html.

Windows is either a registered trademark or a trademark of Microsoft Corporation in the United States and/or other countries. Mac is a trademark of Apple Inc., registered in the United States and other countries. Linux is the registered trademark of Linus Torvalds in the U.S. and other countries.

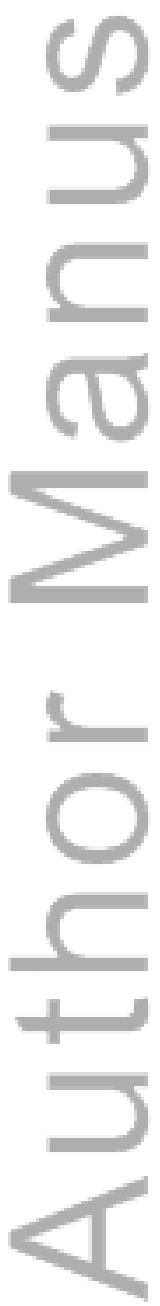




\section{Please wait...}

If this message is not eventually replaced by the proper contents of the document, your PDF viewer may not be able to display this type of document.

You can upgrade to the latest version of Adobe Reader for Windows®, Mac, or Linux® by visiting http://www.adobe.com/go/reader_download.

For more assistance with Adobe Reader visit http://www.adobe.com/go/acrreader.

Windows is either a registered trademark or a trademark of Microsoft Corporation in the United States and/or other countries. Mac is a trademark of Apple Inc., registered in the United States and other countries. Linux is the registered trademark of Linus Torvalds in the U.S. and other countries.
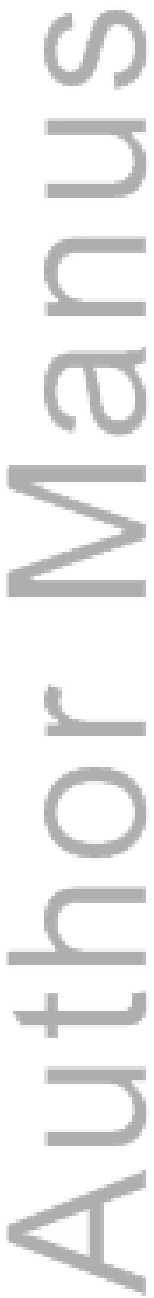


\section{Please wait...}

If this message is not eventually replaced by the proper contents of the document, your PDF viewer may not be able to display this type of document.

You can upgrade to the latest version of Adobe Reader for Windows®, Mac, or Linux® by visiting http://www.adobe.com/go/reader_download.

For more assistance with Adobe Reader visit http://www.adobe.com/go/acrreader.

Windows is either a registered trademark or a trademark of Microsoft Corporation in the United States and/or other countries. Mac is a trademark of Apple Inc., registered in the United States and other countries. Linux is the registered trademark of Linus Torvalds in the U.S. and other countries.
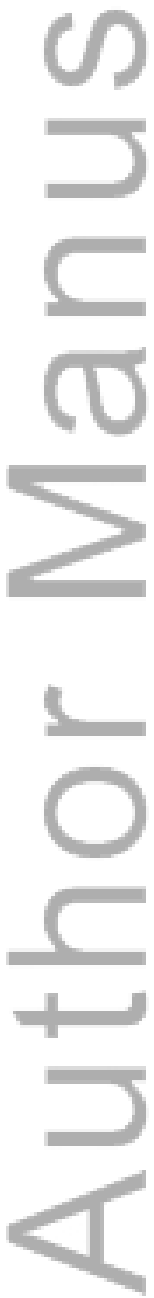
Table 1. Baseline characteristics and behaviors of participants in the High Five for Kids Study Overall and by Intervention Assignment

\begin{tabular}{|c|c|c|c|}
\hline ע & $\begin{array}{l}\text { Overall } \\
n=445\end{array}$ & Intervention & $\begin{array}{c}\text { Usual } \\
\text { Care } \\
n=192\end{array}$ \\
\hline & \multicolumn{3}{|c|}{ Mean (SD) or N (\%) } \\
\hline \multicolumn{4}{|l|}{ Child characteristics } \\
\hline Age, y & $4.9(1.2)$ & $4.8(1.2)$ & $5.2(1.1)$ \\
\hline \multicolumn{4}{|l|}{ Sex, \% } \\
\hline Female & $215(48.3)$ & $121(47.8)$ & $94(49.0)$ \\
\hline Male & $230(51.7)$ & $132(52.2)$ & $98(51.0)$ \\
\hline \multicolumn{4}{|l|}{ Race/ethnicity, \% } \\
\hline White & $252(56.6)$ & $118(46.6)$ & $134(69.8)$ \\
\hline Black & $84(18.9)$ & $70(27.7)$ & $14(7.3)$ \\
\hline Latino & $74(16.6)$ & $48(19.0)$ & $26(13.5)$ \\
\hline Other ) & $35(7.9)$ & $17(6.7)$ & $18(9.4)$ \\
\hline $\mathrm{BMI} \mathrm{kg/ \textrm {m } ^ { 2 }}$ & $19.2(2.3)$ & $19.2(2.6)$ & $19.1(2.0)$ \\
\hline BMI z-score & $1.85(0.63)$ & $1.88(0.69)$ & $1.82(0.56)$ \\
\hline \multicolumn{4}{|l|}{ BMI category, $\%$} \\
\hline 85 th to $<95$ th percentile & $195(43.8)$ & $118(46.6)$ & $77(40.1)$ \\
\hline$\geq 95$ th percentile & $250(56.2)$ & $135(53.4)$ & $115(59.9)$ \\
\hline $\begin{array}{l}\text { Time elapsed from baseline to } 2 \text { year follow-up, } \\
\text { months }\end{array}$ & $26.1(2.3)$ & $26.3(2.4)$ & $25.9(2.1)$ \\
\hline \multicolumn{4}{|l|}{ Child health behaviors } \\
\hline Sugar-sweetened beverage intake, servings/day & $2.1(1.7)$ & $2.3(1.8)$ & $2.0(1.5)$ \\
\hline Fast food consumption, servings/week & $1.1(0.9)$ & $1.2(0.9)$ & $1.1(0.9)$ \\
\hline Total TV and video viewing, hours/day & $2.6(1.5)$ & $2.7(1.6)$ & $2.4(1.3)$ \\
\hline \multicolumn{4}{|l|}{ Parent and household characteristics } \\
\hline \multicolumn{4}{|l|}{ Parent overweight/obesity status, $\%$} \\
\hline Normal weight $(\mathrm{BMI}<25)$ & $17(3.8)$ & $8(3.2)$ & $9(4.7)$ \\
\hline Overweight (BMI 25 to <30) & $189(42.6)$ & $90(35.7)$ & $99(51.6)$ \\
\hline Obese $(\mathrm{BMI} \geq 30)$ & $238(53.6)$ & $154(61.1)$ & $84(43.8)$ \\
\hline \multicolumn{4}{|l|}{ Parent education, \% } \\
\hline Some college or below & $171(38.4)$ & $106(41.9)$ & $65(33.9)$ \\
\hline College graduate & $274(61.6)$ & $147(58.1)$ & $127(66.1)$ \\
\hline \multicolumn{4}{|l|}{ Annual household Income, $\%$} \\
\hline$<\$ 50,000$ & $126(28.7)$ & $88(35.5)$ & $38(19.9)$ \\
\hline$\geq \$ 50,000$ & $313(71.3)$ & $160(64.5)$ & $153(80.1)$ \\
\hline \multicolumn{4}{|l|}{ Marital status, $\%$} \\
\hline Not married & $107(24.0)$ & $66(26.1)$ & $41(21.4)$ \\
\hline Married & $338(76.0)$ & $187(73.9)$ & $151(78.6)$ \\
\hline
\end{tabular}

This article is protected by copyright. All rights reserved. 
Table 2. Change in BMI and health behaviors from baseline to 2 years by intervention assignment

\begin{tabular}{|c|c|c|c|c|c|}
\hline$=$ & Baseline & $\begin{array}{c}2 \text { Years } \\
\text { Mean }(\mathrm{SD})\end{array}$ & Change & $\begin{array}{r}\text { Unadjusted difference }^{\mathrm{a}} \\
\beta(95 \%\end{array}$ & $\begin{array}{l}\text { Adjusted difference }{ }^{\mathrm{b}} \\
\mathrm{CI})\end{array}$ \\
\hline \multicolumn{6}{|l|}{ BMI z-score } \\
\hline Intervention & $1.88(0.69)$ & $1.67(0.67)$ & $-0.20(0.51)$ & \multirow{2}{*}{$-0.02(-0.12,0.07)$} & \multirow{2}{*}{$-0.04(-0.14,0.06)$} \\
\hline Usual care & $1.82(0.56)$ & $1.65(0.60)$ & $-0.18(0.47)$ & & \\
\hline \multicolumn{6}{|l|}{ BMI } \\
\hline Intervention & $19.2(2.6)$ & $20.3(3.6)$ & $1.11(1.99)$ & \multirow{2}{*}{$-0.07(-0.57,0.43)$} & \multirow{2}{*}{$-0.08(-0.53,0.36)$} \\
\hline Usual care & $19.1(2.0)$ & $20.4(2.9)$ & $1.22(1.82)$ & & \\
\hline \multicolumn{6}{|c|}{ Sugar-sweetened beverage intake, servings/d } \\
\hline Intervention & $2.25(1.77)$ & $1.62(1.38)$ & $-0.61(1.71)$ & \multirow{2}{*}{$-0.26(-0.64,0.12)$} & \multirow{2}{*}{$-0.26(-0.67,0.14)$} \\
\hline Usual care & $1.95(1.54)$ & $1.65(1.28)$ & $-0.31(1.22)$ & & \\
\hline \multicolumn{6}{|c|}{ Fast food consumption, servings/wk } \\
\hline Intervention & $1.16(0.93)$ & $0.94(0.72)$ & $-0.23(0.90)$ & \multirow{2}{*}{$-0.13(-0.37,0.12)$} & \multirow{2}{*}{$-0.09(-0.34,0.17)$} \\
\hline Usual care & $1.13(0.90)$ & $1.05(0.83)$ & $-0.08(0.97)$ & & \\
\hline \multicolumn{6}{|c|}{ Total TV and video viewing, $\mathrm{h} / \mathrm{d}$} \\
\hline Intervention & $2.67(1.58)$ & $2.17(1.14)$ & $-0.50(1.54)$ & \multirow{2}{*}{$-0.27(-0.54,0.00)$} & \multirow{2}{*}{$-0.20(-0.49,0.09)$} \\
\hline Usual care & $2.44(1.33)$ & $2.21(1.16)$ & $-0.23(1.22)$ & & \\
\hline
\end{tabular}

${ }^{\mathrm{a}}$ Corrected for clustering within practice

${ }^{\mathrm{b}}$ Adjusted for child age, sex, and race/ethnicity; parent education and overweight/obesity status at baseline; household income; and time elapsed from baseline to 2-year follow-up visit 